1015 VIOLENCE AND WORKING CONDITIONS: FINDINGS FROM A VICTIMISATION SURVEY IN BRAZILIAN MIDSIZED CITY

${ }^{1}$ Magda Helena Reis Cota de Almeida, ${ }^{2}$ Ricardo Tavares, ${ }^{1}$ Elza Machado de Melo, ${ }^{1}$ Andréa Maria Silveira*. ' Universidade Federal de Minas Gerais (UFMG); ' ${ }^{2}$ nniversidade Federal de Ouro Preto (UFOP)

\subsection{6/oemed-2018-ICOHabstracts.393}

Introduction The objective was to analyse the association of violence at work with work conditions.

Methods A questionnaire was applied to 1129 individuals. A correspondence analysis (CA) was performed to verify the association between working conditions and violence. It was done analysis of the association between the type of aggressor and the types of violence.

Results $19.0 \%$ were victims of violence at work. 50.6\% were services workers and $58.3 \%$ came from the formal labour market. Individual external to the workplace committed $34.1 \%$ of violent acts. Boss committed $30.8 \%$ of verbal violence and $25 \%$ of psychological violence. $38.5 \%$ of verbal violence and $25 \%$ of physical violence came from the worker's family member. The CA found a greater association between moral violence and verbal violence in the work at transportation, storage, postal services, education and industry. Physical violence and racism were associated to domestic services and trade.

Discussion The bad working conditions were associated with higher occurrence of violence. These findings point the need for discussion of this issue in Brazil.

\section{THE EXTENT OF SILICA EXPOSURE IN BRAZIL, RUSSIA, INDIA, CHINA AND SOUTH AFRICA}

SD Young. North East Thames Foundation School, London, UK

\subsection{6/oemed-2018-ICOHabstracts.394}

Introduction The risk to health for workers exposed to silica is well established, however the number of workers exposed is less well known, particularly in developing economies. In order to successfully address the issue of exposure and its effects an accurate assessment of the problem is required. The emerging economies of Brazil, Russia, India, China and South Africa (BRICS) are major geopolitical entities with diverse industrial economies, acting as indicators of development in there respective geographical areas, making them ideal as a focal point on which assessments may be focused.

Methods A narrative literature review was performed to provide information regarding the key industrial areas for exposure in each of the BRICS nations. Where available qualitative estimates on the key industries associated with silica exposure in each Nation were determined.

Results Due to similarities in the economic and industrial landscape of the BRICS mining was the most common exposure cause, with high levels also seen in construction and manufacturing. Neither detailed nor approximate records of exposure where available from any of the Nations, although non-industry specific estimates could be accessed for each Nation with the exception of Russia, where very little published information was available.

Conclusion Future efforts to reduce exposure are dependent on an accurate assessment and recording of exposure levels. Currently there is very little large-scale empirical data available from any of the Nations assessed though with the exception of Russia all of the Nations profiled have some publically available records through both academic research and governmental monitoring. From this review it is apparent that further work is required by industry and governments to provide and publish accurate data regarding silica exposure.

\section{EPIDEMIOLOGICAL ANALYSIS CORRELATED WITH SOCIOECONOMIC AND PRODUCTION ASPECTS OF A FACTORY IN SOUTHERN BRAZIL}

Paulo Zetola, Marcelo Bianchi da Silva, Livia Schwab, Edevar Daniel, Aubrey Lopes. Universidade Federal Do Paraná, Curitiba, Brazil

\subsection{6/oemed-2018-ICOHabstracts.395}

Introduction Absenteeism generates several consequences in the manufacturing process. Its reduction is a challenge for any manager. An important step for its understanding, and subsequent reduction and control, is to carry out the analysis of the medical certificates handed by the missing employees. Based on this premise, this paper aims to present the epidemiological profile of 2016 of a company in the automotive sector of the South region of Brazil, as well as the programs and actions taken from these data.

Method An organisational, cross - sectional study developed through data and indicators obtained through the analysis of medical certificates submitted by employees who were absent from work by health reasons in 2016 .

Results A total of 4371 medical certificates were observed, impacting 13409 days of work lost, in a population that varied around 5380 employees. On a monthly measure, 363.9 certificates were obtained, delivered by 238.2 employees, which impacted 1117.9 days lost and 7445.33 hours lost. With these scores, it was possible to define the Frequency Index by Operators (IF2) of 4.42, the Medical Certificate Frequency Index (IF1) of 6.75 and the Severity Index (GI) of 0.8 . Further on the most frequent causes, firstly find the diseases comprised by ICD-10 M, followed by Z, J, S-T and K. When the criterions are the lost days, remains the ICD-10 M followed by Z, S-T and F.

Discussion The results are similar to the data found in the literature and allow a good correlation with the socioeconomic aspects of the country. The production data are consistent with the variation in the pace of work and entry of new projects. Health promotion in a comprehensive way contributes to the biopsychosocial well-being of employees, as well as their satisfaction and working commitment.

\section{ASBESTOS-RELATED DISEASES IN CURITIBA: THE BRAZIL-ITALY PROJECT}

${ }^{1} \mathrm{D}$ Consonni*, ${ }^{2} \mathrm{LP}$ Puchalski Kalinke, ${ }^{3} \mathrm{MA}$ Kalinke, ${ }^{2}$ FMoura D'Almeida Miranda, ${ }^{2} \mathrm{~L}$ Marcondes, ${ }^{2} \mathrm{~T}$ Hallfeld, ${ }^{2} \mathrm{C}$ Brey, ${ }^{2} \mathrm{~S}$ Boller, ${ }^{1,4} \mathrm{AC}$ Pesatori, ${ }^{1} \mathrm{C}$ Mensi, ¿LMMansano Sarquis. 'Epidemiology Unit, Fondazione IRCCS Ca' Granda Ospedale Maggiore Policlinico, Milan, Italy; ${ }^{2}$ Universidade Federal do Paranà, Curitiba, Brazil; ${ }^{3}$ Universidade Tecnológica Federal do Paranà, Curitiba, Brazil; ${ }^{4}$ Department of Clinical Sciences and Community Health, Università degli Studi di Milano, Milan, Italy

\subsection{6/oemed-2018-ICOHabstracts.396}

Introduction Brazil is one of the major producers of chrysotile, a well-known carcinogen, but few studies evaluated its impact locally. For these reasons, a joint project, supported by CAPES, Brasilia, was started between the Federal University of 